\title{
Laboratory characteristics of HIV-1 clade C-infected long-term non-progressors at a tertiary human immunodeficiency virus care centre in South India
}

More than two decades since the discovery of the human immunodeficiency virus (HIV), the aetiological agent of AIDS, the pandemic continues to expand. The predictable clinical course of the illness is characterized by an initial symptomatic disease that mimics infectious mononucleosis, followed by an asymptomatic period of approximately 8-10 years in untreated persons, during which time there is ongoing viral replication and progressive loss of $\mathrm{CD} 4^{+}$ T-lymphocytes. Most antiretroviral (ARV) naive individuals eventually develop immunodeficiency and die from AIDS-related complications, with time to death being $\sim 10$ years after becoming infected. The vast majority of ARV naive individuals exhibit evidence of ongoing viral replication and progressive $\mathrm{CD} 4{ }^{+}$ T-lymphocyte depletion. However, a small proportion of infected subjects (5-15\%) remain clinically and/or immunologically stable for years. These persons remain AIDS free in spite of years of HIV infection and are referred to as 'long-term non-progressors' (LTNPs) (Cao et al., 1995; Munoz et al., 1995; Pantaleo et al., 1995). LTNPs are characterized by documented HIV infection for over 7 years, a stable CD4 ${ }^{+}$T-lymphocyte count over time and $>600$ T-lymphocyte cells $\mu \mathrm{l}^{-1}$, low levels of cell-free virus in peripheral blood, no symptoms or signs of HIV-induced immunosuppression and no history of ARV therapy (Sheppard et al.,1993; Lifson et al., 1991; Levy, 1993). These subjects with greater immune control can serve as better models for studying the role of host factors in HIV infection. However, inter-individual variability and other existing cofactors warrant intensive and long-term research in order to identify LTNPs among the general HIV-infected population.

The AIDS pandemic is particularly serious in India, where HIV-1 clade C is widely distributed (Sheppard et al., 1993). Attempts to generate a vaccine seem to have challenged the scientific community for over 25 years since the discovery of HIV-1. Conceptually, the generation of any successful vaccine requires the understanding of features consistent to the virus, and would depend on multiple factors, including viral and host immunogenetic features, as exemplified by HIV-1 infection. The preliminary characteristics necessary to define LTNPs in third-world countries, especially in the Indian scenario, are inadequate. Therefore, we studied the virological, microbiological and immunological characteristics of LTNPs $(n=12)$ and progressors $(n=12)$ with HIV-1 clade C infection at Y R Gaitonde Centre for AIDS Research and Education (YRG CARE), a tertiary HIV referral centre in Chennai, South India. Since 1993, the centre has provided medical and psychosocial care to over $11000 \mathrm{HIV}$-infected individuals in the region, and has been conducting vaccine and clinical trials in the south of India since 2001, and is funded by the National Institutes of Health and other organizations in the United States. YRG CARE's clinical and research laboratory has been participating in the external quality assessment programmes of the UK-National External Quality Assessment Scheme for immunophenotyping, National Serology Reference Laboratory, Australia, and the College of American Pathologists, USA, and has been certified with Good Clinical Laboratory Practices compliance since 2001.

The criteria used to define nonprogression included individuals with a CD4 ${ }^{+}$T-lymphocyte count of $>400$ cells $\mu^{-1}$ for $>7$ years, asymptomatic and ARV naive (Sheppard et al., 1993; Lifson et al., 1991; Levy, 1993). Age, CD4 ${ }^{+}$ T-lymphocyte percentage, $\mathrm{CD} 4^{+} / \mathrm{CD} 8^{+}$ T-lymphocyte ratio and $\mathrm{CD} 8^{+}$

T-lymphocyte count, haemoglobin percentage $(\mathrm{Hb} \%)$ and body weight of the LTNPs were compared with progressors of HIV-1 infection to determine the factors that influenced disease progression. Progressors were subjects that developed AIDS with a gradual decline in $\mathrm{CD} 4^{+}$ T-lymphocyte counts to $<400$ cells $_{\mu \mathrm{l}^{-1}}$ after 5 years of HIV-1 infection (Sheppard et al., 1993).

Routine microbiological and clinical investigations were carried out using standard laboratory methods. CD4 ${ }^{+}$ T-lymphocyte profile and plasma viral load (PVL) were determined using a FACSCount flow cytometry assay (Becton Dickinson) and a PVL (COBAS-Amplicor) analyser, respectively. Haemoglobin levels were estimated using the three-part Sysmex-K21 haemato-analyser (Kobe). Statistical analysis was done using the Statistical Package for Social Sciences software, version 13.0 (SPSS).

The demographic details, and clinical and laboratory characteristics of the study groups are presented in Table 1. We found that $\mathrm{CD} 4{ }^{+} \mathrm{T}$-lymphocyte percentage was associated with HIV-1 disease progression and the median $\mathrm{CD} 4^{+}$T-lymphocyte percentage in LTNPs and progressors were 26 and $16 \%$, respectively. HIV genotype, $\mathrm{Hb} \%$ and body weight were not associated with disease progression. The PVL available from LTNPs and progressors ranged between 5000 and 6000 copies $\mathrm{ml}^{-1}$ and $>750000$ copies $\mathrm{ml}^{-1}$ (range 500 000-750 000), respectively. The median $\mathrm{CD} 4{ }^{+} \mathrm{T}$-lymphocyte percentage agrees with recent findings that HIV positive persons with a median $\mathrm{CD} 4{ }^{+}$ T-lymphocyte percentage $<17$ had a greater risk of rapid disease progression as compared to those persons with a percentage $>17$ (Pirzada et al., 2006; Hulgan et al., 2005).

No association with disease progression was seen with regards to age, gender, 
Table 1. Demographic, virological and immunological characteristics of LTNPs $(n=12)$ and progressors $(n=12)$ of HIV infection in Chennai, South India

\begin{tabular}{|c|c|c|}
\hline Characteristic & LTNP & Progressor \\
\hline \multicolumn{3}{|l|}{ Gender* } \\
\hline Male (\%) & $8(67)$ & $9(75)$ \\
\hline Female (\%) & $4(33.3)$ & $3(25)$ \\
\hline Mean age (years) & 28 & 30 \\
\hline \multicolumn{3}{|l|}{ Mode of transmission* } \\
\hline Heterosexual & $10(83.3)$ & $11(91.6)$ \\
\hline Blood transfusion & $2(17)$ & $1(8.3)$ \\
\hline \multicolumn{3}{|c|}{ Opportunistic infections/microbiological diagnosis ${ }^{\star}$} \\
\hline Oral candidiasis & None & $4(33.3)$ \\
\hline Pulmonary tuberculosis & None & $5(42)$ \\
\hline Extrapulmonary tuberculosis & None & $1(8.3)$ \\
\hline Pneumocystis pneumonia & None & $2(17)$ \\
\hline Herpes simplex & None & $1(8.3)$ \\
\hline Toxoplasmosis & None & $\mathrm{NA}$ \\
\hline Cryptococcus meningitis & None & $\mathrm{NA}$ \\
\hline Cytomegalovirus retinitis & None & $\mathrm{NA}$ \\
\hline \multicolumn{3}{|l|}{ Laboratory markers/immunological profile $\dagger$} \\
\hline $\mathrm{CD}^{+}$T-lymphocyte count $\left(\right.$cells $\left.\mu \mathrm{l}^{-1}\right)$ & $716(602-1064)$ & $247(173-586)$ \\
\hline $\mathrm{CD}^{+}$T-lymphocyte percentage $\ddagger$ & $26(24-37)$ & $16(9-25)$ \\
\hline $\mathrm{CD}^{+} / \mathrm{CD} 8^{+}$lymphocyte ratio & $0.52(0.36-0.93)$ & $0.42(0.22-0.62)$ \\
\hline $\mathrm{Hb} \%$ & $12(10.1-13)$ & $12.3(10.2-13)$ \\
\hline Body weight & $63(56-73)$ & $56(44-60)$ \\
\hline PVL $\left(\right.$ copies $\left.\mathrm{ml}^{-1}\right) \dagger \ddagger$ & $5500(5000-6000)$ & $750000(500000-750000)$ \\
\hline
\end{tabular}

NA, Not available; none, tested but not observed.

${ }^{\star}$ Entries are expressed as number (percentage).

$\dagger$ Entries are expressed as median (interquartile range).

$\ddagger P$ value $<0.05$.

$\mathrm{CD} 4^{+} / \mathrm{CD} 8^{+}$T-lymphocyte ratio and $\mathrm{CD}^{+}{ }^{+}$absolute counts, similar to results documented by others (Pirzada et al., 2006). The PVL details suggest that LTNPs have better immune control over HIV viral replication than other HIV-infected subjects (Sheppard et al., 1993; Lifson et al., 1991; Levy, 1993). The criteria defining LTNPs may vary with the geographical locality and should be adapted based on the pattern of disease progression, as a substantial variation in the rates of disease progression has been observed across countries (Kumarasamy et al., 2003; Hira et al., 2003; Rutherford et al., 1990). Inclusion of HIV-1 RNA values below detection seems to be mandatory. We found that none of the factors were associated with non-progression, except $\mathrm{CD}^{+}{ }^{+}$T-lymphocyte percentage and a PVL $<6000$ copies $\mathrm{ml}^{-1}$. The LTNPs would serve as valuable models for monitoring disease progression and vaccine research. Further efforts are being made to measure the level of broadly neutralizing antibodies and cell-mediated immune responses in the HIV-1 clade $\mathrm{C}$-infected subjects. However, more studies may be required in clade $\mathrm{C}$ prevalent Indian settings to better understand the dynamics and magnitude of host immune factors in LTNPs.

\section{Uma Shanmugasundaram, Kailapuri G. Murugavel, Esaki Muthu Shankar, Pachamuthu Balakrishnan, Suniti Solomon and Nagalingeswaran Kumarasamy}

Y. R. Gaitonde Centre for AIDS Research and Education, Voluntary Health Services Campus, Taramani, Chennai 600113, India.

Correspondence: Nagalingeswaran Kumarasamy (kumarasamy@yrgcare.org)
Cao, Y., Qin, L., Zhang, L., Safrit, J. \& Ho, D. D. (1995). Virologic and immunologic characterization of long-term survivors of human immunodeficiency virus type 1 infection. N Engl J Med 332, 201-208.

Hira, S. K., Shroff, H. J., Lanjewar, D. N., Dolkhia, Y. N., Bhatia, V. P. \& Dupont, H. L. (2003). The natural history of human immunodeficiency virus infection among adults in Mumbai. Natl Med J India 16, 126-130.

Hulgan, T., Raffanti, S., Kheshti, A., Blackwell, R. B., Rebeiro, P. F., Barkanic, G., Ritz, B. \& Sterling, T. R. (2005). CD4 lymphocyte percentage predicts disease progression in HIV infected patients initiating highly active antiretroviral therapy with CD4 lymphocyte counts >350 lymphocytes/ $\mathrm{mm}^{3}$. J Infect Dis 192, 950-957.

Kumarasamy, N., Solomon, S., Flanigan, T. P., Hemalatha, R. \& Thyagarajan, S. P. (2003). Natural history of human immunodeficiency virus disease in southern India. Clin Infect Dis 36, 79-85.

Levy, J. A. (1993). HIV pathogenesis and long term survival. AIDS 7, 1401-1410.

Lifson, A. R., Buchbinder, S., Sheppard, H. W., Mawle, A. C., Wilber, J. C., Stanley, M., Hart, C. E., Hessol, N. A. \& Holmberg, S. D. (1991). 
Long-term human immunodeficiency virus infection in asymptomatic homosexual and bisexual men with normal $\mathrm{CD} 4{ }^{+}$lymphocyte counts: immunologic and virologic characteristics. J Infect Dis 163, 959-965.

Munoz, A., Kirby, A. J., He, Y. D., Margolick, J. B., Visscher, B. R., Rinaldo, C. R., Kaslow, R. A. \&

Phair, J. P. (1995). Long-term survivors with HIV-

1 infection: incubation period and longitudinal patterns of $\mathrm{CD} 4{ }^{+}$lymphocytes. J Acquir Immune Defic Syndr Hum Retrovirol 8, 496-505.
Pantaleo, G., Menzo, S., Vaccarezza, M., Graziosi, C., Cohen, O. J., Demarest, J. F., Montefiori, D., Orenstein, J. M., Fox, C. \& other authors (1995). Studies in subjects with longterm nonprogressive human immunodeficiency virus infection. N Engl J Med 332, 209-216.

Pirzada, Y., Khuder, S. \& Donabedian, H. (2006). Predicting AIDS-related events using CD4 percentage or CD4 absolute counts. AIDS Res Ther 3, 20.
Rutherford, G. W., Lifson, A. R., Hessol, N. A., Darrow, W. W., O'Malley, P. M., Buchbinder, S. P., Barnhart, J. L., Bodecker, T. W., Cannon, L. \& other authors (1990). Course of HIV-1 infection in a cohort of homosexual and bisexual men: a 11-year follow up study. BMJ 301, 1183-1188.

Sheppard, H. W., Lang, W., Ascher, M. S., Vittinghoff, E. \& Winkelstein, W. (1993). The characterization of non-progressors: long-term HIV-1 infection with stable CD $4^{+}$T-cell levels. AIDS 7, 1159-1166. 